\title{
Pengaruh Pencahayaan Buatan Terhadap Persepsi dan Pengalaman Pengunjung di Taman Kota Sewaka Dharma
}

\author{
Kadek Sri Wulandhari¹, I Gusti Agung Ayu Rai Asmiwyati , Ni Luh Made Pradnyawathi² \\ 1. Prodi Arsitektur Lanskap, Fakultas Pertanian Universitas Udayana, Indonesia 80232 \\ 2. Prodi Agroekoteknologi, Fakultas Pertanian Universitas Udayana, Indonesia 80232 \\ *E-mail: asmiwyati@unud.ac.id
}

\begin{abstract}
The effect of artificial lighting on visitors' perceptions and experiences in Sewaka Dharma City Park. Lighting is one factor that is quite important in a garden because it can make the environment comfortable and safe, especially at night. Sewaka Dharma City Park is a green open space in Denpasar which is equipped with various lighting facilities with aesthetic values. This study aims to identify the type and placement of artificial lighting, determine the perceptions and experiences of visitors to artificial lighting from the aspect of human needs and provide recommendations for artificial lighting designs in Sewaka Dharma City Park. The data collection methods used were observation, questionnaires, interviews, and literature study with tabulated data analysis, Chi-square test and descriptive analysis. There are eleven types of existing lights located in the pathway area, lawn, CPG (Children Playground), and youth park. The Chi-Square test shows that artificial lighting affects visibility and visual comfort aspects, but does not affect the visitor's security experience, which can also be interpreted that artificial lighting in Sewaka Dharma City Park fulfills security aspects so as to minimize unsafe actions for visitors. This study recommends the types and placements of artificial lighting in areas that have a high influence in supporting human needs from the aspect of visibility and visual comfort, namely in the CPG area and youth park.
\end{abstract}

Keywords: Artificial Lighting, Chi-Square, Sewaka Dharma City Park

\section{Pendahuluan}

Taman jika ditinjau dari aspek desain memiliki unsur titik, garis, bentuk, bidang, ruang, warna, tekstur dan cahaya. Unsur cahaya merupakan salah satu faktor penting di dalam sebuah taman karena dapat membuat lingkungan menjadi nyaman dan aman bagi pengunjung dalam melakukan aktivitas. Pencahayaan yang baik memudahkan seseorang untuk melihat objek-objek yang ada. Pencahayaan dapat dibagi menjadi dua yaitu pencahayaan alami yang berasal dari matahari, dan pencahayaan buatan yang dibuat dengan campur tangan manusia. Pencahayaan buatan memiliki peran sangat penting saat malam hari (Handayani, 2009).

Taman Kota Sewaka Dharma merupakan salah satu ruang terbuka hijau publik di Denpasar yang memiliki pencahayaan buatan menarik karena dilengkapi dengan lampu bernilai estetika. Fasilitas yang tersedia di Taman Kota Sewaka Dharma terbagi atas beberapa ruang. Setap ruang dibatasi oleh vegetasi yang menyebabkan intensitas pencahayaan pada malam hari menjadi kurang maksimal. Selain itu terdapat beberapa area yang memiliki jumlah lampu banyak namun cahaya yang dihasilkan tidak mampu menerangi area dengan baik. Hal ini berpengaruh terhadap kebutuhan manusia seperti jarak pandang, kenyamanan visual dan keamanan yang dipengaruhi pencahayaan buatan tidak dapat terpenuhi dalam suatu ruang, sehingga pengunjung tidak dapat melakukan aktivitasnya dengan baik (Rea, 2000). Penelitian ini bertujuan untuk mengidentifikasi jenis dan penempatan pencahayaan buatan, mengetahui persepsi dan pengalaman pengunjung terhadap pencahayaan buatan dari aspek kebutuhan manusia dan memberi rekomendasi desain pencahayaan buatan di Taman Kota Sewaka Dharma.

\section{Metode Penelitian}

\subsection{Lokasi Penelitian}

Penelitian ini berlokasi di Taman Kota Sewaka Dharma, Desa Pakraman Dauh Puri Kaja, Denpasar Utara, Kota Denpasar, Bali (Gambar 1). 


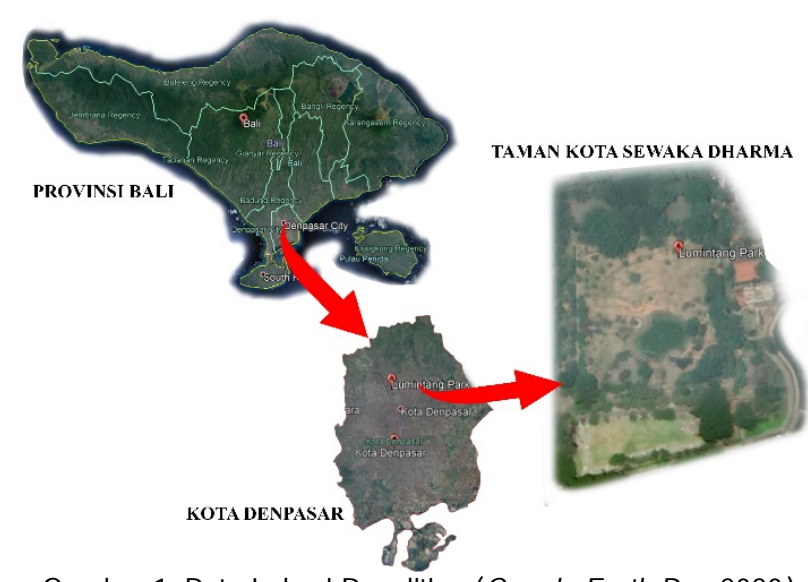

Gambar 1. Peta Lokasi Penelitian (Google Earth Pro, 2020)

\subsection{Bahan dan Alat}

Bahan dan alat yang digunakan dalam penelitian ini adalah kuisioner, alat tulis, telepon genggam, dan komputer dengan software Microsoft Word, Microsoft Excel, IBM SPSS Statistics versi 24.0 for Windows, Google Earth, dan Adobe Photoshop CS6, Sketch Up 2018, Lumion 8.0.

\subsection{Pengumpulan Data}

Jenis data yang digunakan dalam penelitian ini yaitu data primer dan data sekunder. Data primer merupakan data yang diperoleh melalui kegiatan observasi untuk mencari data mengenai kondisi fisik pencahayaan buatan dan jenis-jenis pencahayaan buatan, kegiatan wawancara ditujukan kepada kepala Bagian Pertamanan Dinas Perumahan, Kawasan Pemukiman dan Pertanahan Kota Denpasar untuk mengetahui gambaran umum dan pemeliharaan lampu di Taman Kota Sewaka Dharma. Pengumpulan data kuesioner ditujukan kepada pengunjung yang dipilih secara acak tidak ditentukan oleh kriteria khusus. Pertanyaan pada kuesioner terkait aspek kebutuhan manusia melalui komponen jarak pandang untuk mengetahui apakah pencahyaan buatan mampu memenuhi jarak pandang pengunjung dalam mendukung aktivitas, kenyamanan visual untuk mengetahui apakah pencahayaan buatan mampu memberikan rasa nyaman atau terganggu dengan intensitas cahaya eksisting dan aspek keamanan untuk mengetahui pengalaman pengunjung terkait bahaya atau ancaman yang dipengaruhi oleh pencahayaan buatan. Pembagian kuesioner dilakukan pada tanggal 21 Februari 2020 hingga 5 Maret 2020 pada pukul 19.00 WITA hingga 21.00 WITA. Total responden yang dibagikan kuesioner yaitu sebanyak 200 orang pengunjung dengan membagi area menjadi empat. Pembagian area ini dibagi berdasarkan aktivitas dominan yang dilakukan oleh pengunjung di antaranya yaitu pathway (jalan setapak) dengan aktivitas dominan pengunjung yaitu berjalanjalan, lawn (lapangan rumput) dengan aktivitas dominan pengunjung yaitu duduk-duduk, CPG (Children Playground) dengan aktivitas dominan pengunjung yaitu bermain dengan fasilitas permainan yang telah tersedia dan youth park dengan aktivitas dominan pengunjung yaitu berkreativitas dengan menggunakan fasilitas-fasilitas yang tersedia. Jumlah responden yang digunakan dalam setiap area yaitu sebanyak 50 orang pengunjung, ini ditentukan dari jumlah minimal responden pada kuesioner yaitu 30 orang, untuk mendapatkan hasil yang variatif dan perhitungan yang lebih akurat dilakukan pembagian responden sebanyak 50 orang dalam setiap area.

\subsection{Analisis Data}

Metode analisis data yang digunakan dalam penelitian ini adalah tabulasi. Berdasarkan Soegoto (2013) metode analisis tabulasi dalam penelitian ini digunakan untuk mengolah data kuesioner ke dalam bentuk persentase dengan dirumuskan:

$P=f / N \times 100 \%$.

Keterangan:

$\mathrm{P}=$ Persentase

$f=$ Frekuensi

$N=\sum$ Total Responden 
Selanjutnya dilakukan uji statistika untuk mengolah dan menjelaskan data kuantitatif. Metode statistika yang digunakan adalah uji Chi-square untuk menguji hubungan dan pengaruh antara dua buah variabel nominal yaitu pencahayaan buatan di Taman Kota Sewaka Dharma dengan aspek kebutuhan (jarak pandang, kenyamanan visual dan keamanan). Uji Chi-Square dapat dirumuskan sebagai berikut Hadi (2000):

$\mathrm{x}^{2}=\sum_{i=1}^{n} \frac{(O i-E i)^{2}}{E i}$

$x^{2}=$ Distribusi Chi-Square

Oi = Nilai observasi ke-i

$\mathrm{Ei}=$ Nilai ekspektasi ke-i

Adapun langkah-langkah dalam pengujian Chi-Square yaitu:

1 Merumuskan hipotesis $\mathrm{HO}$ dan $\mathrm{H} 1$

$\mathrm{HO}$ : Tidak terdapat pengaruh signifikan dari dua variabel

$\mathrm{H} 1$ : Terdapat pengaruh signifikan dari dua variabel

2 Mencari nilai frekuensi harapan (EI)

Ei setiap sel $=\frac{(\text { Total } \text { Baris }) \text { (Total } \text { Kolom })}{\text { Total } \text { Keseluruhan }}$.

3 Menghitung distribusi dari Chi-Square

4 Menentukan taraf signifikansi a

5 Menentukan nilai $x^{2}$ tabel

Taraf signifikansi $(\mathrm{a})=0,05$

d. $f=($ Jumlah baris -1$)($ Jumlah kolom -1$)$

6 Menentukan kriteria pengujian

Jika $x^{2}$ hitung $<x^{2}$ tabel, maka HO Diterima

Jika $x^{2}$ hitung $>x^{2}$ tabel, maka HO Ditolak

Jika $p$-value atau Asymp. Sig. $>0,05$ maka H0 Diterima

Jika $p$-value atau Asymp. Sig. $<0,05$ maka H0 Ditolak

7 Membandingkan $\mathrm{x}^{2}$ hitung dengan $\mathrm{x}^{2}$ tabel atau Asymp. Sig. dengan a (Melihat hasil H0 ditolak atau diterima)

8 Membuat kesimpulan (Ada atau tidaknya pengaruh antar variable)

Analisis deskriptif digunakan untuk menjelaskan dan menarasikan data ke dalam bentuk informasi yang ringkas. Analisis deskriptif dalam penelitian ini digunakan untuk menjelaskan data hasil observasi dan hasil penelitian yaitu rekomendasi menjadi informasi berbentuk narasi (Istijanto, 2005).

\subsection{Batas Penelitian}

Penelitian ini dilaksanakan pada area lawn, pathway, CPG dan youth park di Taman Kota Sewaka Dharma. Kuesioner pada penelitian ini dibatasi mengenai jarak pandang, kenyamanan visual dan keamanan terhadap persepsi dan pengalaman pengunjung. Penyebaran kuesioner dan observasi mengenai efek cahaya dilakukan pada malam hari.

\section{Hasil dan Pembahasan}

\subsection{Gambaran Umum}

Taman Kota Sewaka Dharma merupakan salah satu dari ruang terbuka hijau publik yang dimiliki Kota Denpasar. Taman ini berlokasi di Jalan Gatot Subroto Tengah dan jalan Mulawarman, Lumintang, Dauh Puri Kaja, Denpasar Utara, Kota Denpasar. Berdasarkan citra google earth, 2020 diketahui bahwa Taman Kota Sewaka Dharma memiliki luas sebesar $21.038 \mathrm{~m} 2$ dan dilengkapi dengan berbagai fasilitas ruang dengan elemen softscape dan hardscape yang difungsikan untuk menunjang kebutuhan pengunjung seperti lapangan, kolam air mancur, CPG, youth park dan jogging track.

\subsection{Kondisi Pencahayaan Buatan Taman Kota Sewaka Dharma}

Lampu-lampu yang ada di Taman Kota Sewaka Dharma jika ditinjau berdasarkan sumber material terbagi menjadi tiga jenis yaitu fluoresens yang disimbolkan dengan tipe A, HID (High Intensity Discharge) yang disimbolkan dengan tipe $B$, dan LED (Light Emmiting Diode) yang disimbolkan dengan tipe C. Terdapat satu tipe lampu fluoresens di Taman Kota Sewaka Dharma yang ditinjau berdasarkan arah pencahayaan, kebutuhan dan fungsi, satu tipe lampu HID serta sembilan tipe lampu LED. Jenis lampu yang terdapat di Taman 
Kota Sewaka Dharma dirangkum ke dalam Tabel 1, dan lampu eksisting Taman Kota Sewaka Dharma seperti pada Gambar 2.

Tabel 1. Jenis lampu yang terdapat di Taman Kota Sewaka Dharma

\begin{tabular}{|c|c|c|c|c|c|c|c|c|c|c|c|c|}
\hline \multirow[t]{2}{*}{ No. } & \multirow[t]{2}{*}{ Kode } & \multicolumn{3}{|c|}{$\begin{array}{c}\text { Lampu } \\
\text { Berdasarkan Sumber }\end{array}$} & \multicolumn{4}{|c|}{$\begin{array}{c}\text { Lampu } \\
\text { Berdasarkan Arah }\end{array}$} & \multicolumn{3}{|c|}{$\begin{array}{c}\text { Lampu } \\
\text { Berdasarkan Kebutuhan }\end{array}$} & \multirow{2}{*}{$\begin{array}{l}\text { Fungsi Lampu pada } \\
\text { Taman Kota Sewaka } \\
\text { Dharma }\end{array}$} \\
\hline & & Fluoresens & $H I D$ & LED & Atas & Bawah & Samping & $\begin{array}{c}\text { Wall } \\
\text { Washer }\end{array}$ & Umum & Aksen & Efek & \\
\hline 1 & A & $\sqrt{ }$ & & & & $\sqrt{ }$ & & & $\sqrt{ }$ & & & Penerangan ruangan \\
\hline 2 & B & & $\sqrt{ }$ & & & $\sqrt{ }$ & & & $\sqrt{ }$ & & & $\begin{array}{l}\text { Penerangan jalan/ } \\
\text { pathway }\end{array}$ \\
\hline 3 & $\mathrm{C} 1$ & & & $\sqrt{ }$ & & $\sqrt{ }$ & & & $\sqrt{ }$ & & & $\begin{array}{l}\text { Penerangan jalan/ } \\
\text { pathway }\end{array}$ \\
\hline 4 & $\mathrm{C} 2$ & & & $\sqrt{ }$ & & $\sqrt{ }$ & & & $\sqrt{ }$ & & & Penerangan lawn \\
\hline 5 & C3 & & & $\sqrt{ }$ & & $\sqrt{ }$ & $\sqrt{ }$ & & & & $\sqrt{ }$ & Penerangan estetika \\
\hline 6 & $\mathrm{C} 4$ & & & $\sqrt{ }$ & $\sqrt{ }$ & & $\sqrt{ }$ & & & $\sqrt{ }$ & & $\begin{array}{l}\text { Penerangan suatu } \\
\text { objek }\end{array}$ \\
\hline 7 & C5 & & & $\sqrt{ }$ & $\sqrt{ }$ & & & $\sqrt{ }$ & & $\sqrt{ }$ & & $\begin{array}{l}\text { Penerangan suatu } \\
\text { objek }\end{array}$ \\
\hline 8 & $\mathrm{C} 6$ & & & $\sqrt{ }$ & & & $\sqrt{ }$ & & & $\sqrt{ }$ & & Penerangan tangga \\
\hline 9 & $\mathrm{C} 7$ & & & $\sqrt{ }$ & $\sqrt{ }$ & $\sqrt{ }$ & & & & & $\sqrt{ }$ & $\begin{array}{l}\text { Penerangan tiang } \\
\text { penyangga }\end{array}$ \\
\hline 10 & $\mathrm{C} 8$ & & & $\sqrt{ }$ & $\sqrt{ }$ & & & & & & $\sqrt{ }$ & $\begin{array}{l}\text { Penerangan air } \\
\text { mancur }\end{array}$ \\
\hline 11 & $\mathrm{Cg}$ & & & $\sqrt{ }$ & & & $\sqrt{ }$ & & & $\sqrt{ }$ & & Penerangan tangga \\
\hline
\end{tabular}
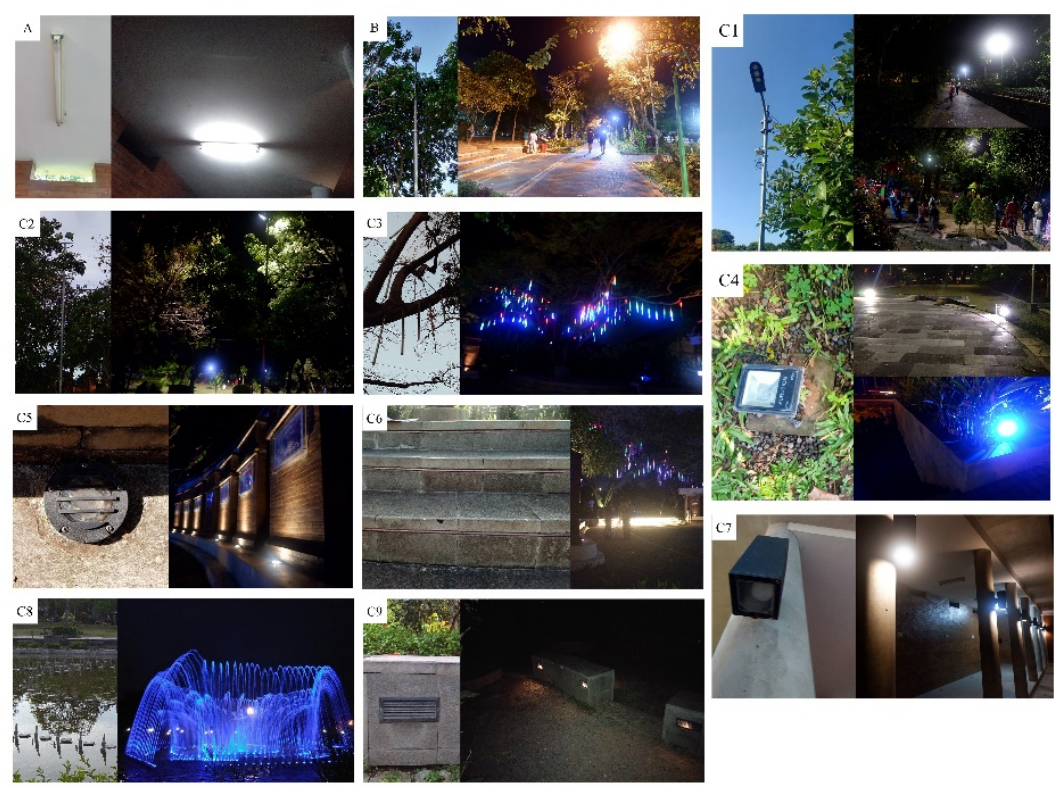

Gambar 2. Lampu Eksisting di Taman Kota Sewaka Dharma

1. Lampu tipe A di Taman Kota Sewaka Dharma berjumlah 17 buah, tersebar untuk menerangi seluruh area food center youth park dan sekitarnya. Kondisi lampu ini di Taman Kota Sewaka Dharma menyala baik.

2. Lampu tipe B di Taman Kota Sewaka Dharma berjumlah 4 (empat) buah, tersebar di beberapa titik area pathway yang gelap. Kondisi lampu ini di Taman Kota Sewaka Dharma menyala dengan baik. 
3. Lampu tipe C1 di Taman Kota Sewaka Dharma berjumlah 38 buah, tersebar di seluruh area pathway, di beberapa titik area lawn, dan juga area CPG. Kondisi lampu ini di Taman Kota Sewaka Dharma sebagian besar menyala dengan baik, namun beberapa lampu tampak tidak menyala.

4. Lampu tipe C2 di Taman Kota Sewaka Dharma berjumlah 2 (dua) buah, terdapat di area lawn bagian utara. Kondisi lampu ini di Taman Kota Sewaka Dharma menyala dengan baik.

5. Lampu tipe C3 di Taman Kota Sewaka Dharma digantung di 9 (sembilan) pohon area youth park, seperti dekat entrance youth park, amphitheater, panggung, dan dekat food center youth park. Kondisi lampu ini di Taman Kota Sewaka Dharma menyala dengan baik.

6. Lampu tipe C4 di Taman Kota Sewaka Dharma berjumlah 19 buah. Lampu ini merupakan lampu LED dengan tipe pencahayaan aksen, tersebar dan menyorot ke beberapa vegetasi berstrata pohon dan semak di area youth park, selain itu juga terdapat di panggung Taman Kota Sewaka Dharma. Kondisi lampu ini di Taman Kota Sewaka Dharma menyala dengan baik.

7. Lampu tipe C5 di Taman Kota Sewaka Dharma berjumlah 17 buah tersebar dan menyorot ke arah pameran foto yang ada di area youth park. Kondisi lampu ini di Taman Kota Sewaka Dharma menyala dengan baik.

8. Lampu tipe $\mathrm{C} 6$ dipasang di 3 (tiga) buah anak tangga panggung youth park dan di dalam tulisan plang nama youth park. Kondisi lampu ini di Taman Kota Sewaka Dharma terlihat tidak menyala, sehingga gambar yang ditampilkan bersumber dari internet.

9. Lampu tipe C7 di Taman Kota Sewaka Dharma berjumlah 19 buah diletakkan di tiang penyangga food center youth park. Kondisi lampu ini di Taman Kota Sewaka Dharma menyala dengan baik.

10. Lampu tipe C8 tersebar di air mancur Taman Kota Sewaka Dharma. Kondisi lampu ini hanya menyala setiap hari jumat, sabtu, dan minggu.

11. Lampu tipe C9 di Taman Kota Sewaka Dharma berjumlah 46 buah tersebar di tangga area youth park menuju jogging track di pinggir Sungai Tagtag dan di beberapa planterbox youth park. Kondisi lampu ini di Taman Kota Sewaka Dharma sebagian besar menyala dengan baik, namun beberapa lampu tampak tidak menyala.

\subsection{Kondisi Sosial Taman Kota Sewaka Dharma}

Taman Kota Sewaka Dharma merupakan ruang terbuka hijau publik yang ramai dikunjungi oleh masyarakat Kota Denpasar karena letaknya yang sangat strategis. Gambar 3 menunjukkan berbagai aktivitas yang dilakukan oleh pengunjung di Taman Kota Sewaka Dharma pada malam hari.

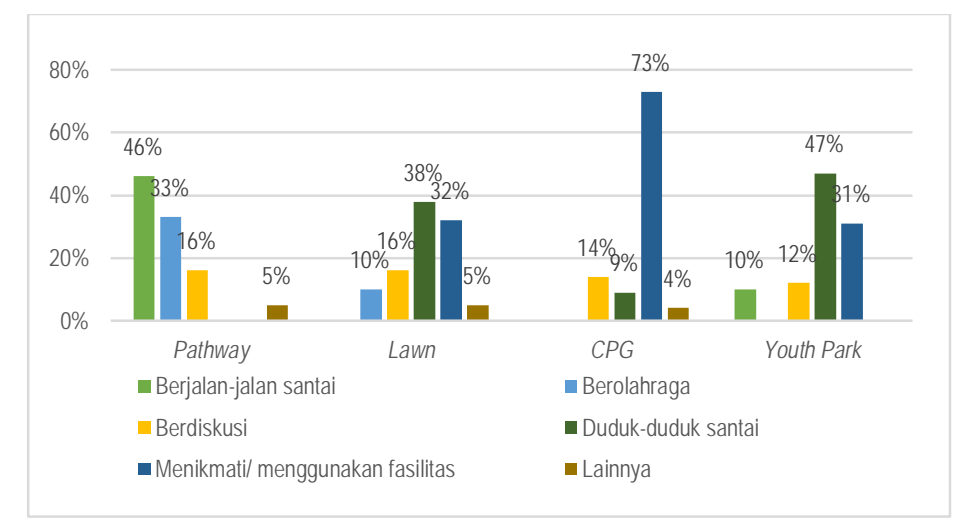

Gambar 3. Diagram Aktivitas Pengunjung di Taman Kota Sewaka Dharma

Berdasarkan hasil data yang diperoleh, aktivitas dominan dari pengunjung sudah sesuai dengan fungsi pada setiap area, maka pada setiap area ditunjang dengan pencahayaan buatan yang sesuai dengan kebutuhan aktivitas di setiap area.

\subsection{Pencahayaan Buatan di Taman Kota Sewaka Dharma berdasarkan Aspek Jarak Pandang}

Persepsi pengunjung mengenai pencahayaan buatan di Taman Kota Sewaka Dharma pada malam hari jika ditinjau berdasarkan aspek jarak pandang diidentifikasi secara spesifik pada ruang taman kota dengan 
membagi area Taman Kota Sewaka Dharma menjadi empat bagian, sedangkan aspek jarak pandang dibagi menjadi tiga bagian seperti pada Gambar 4.

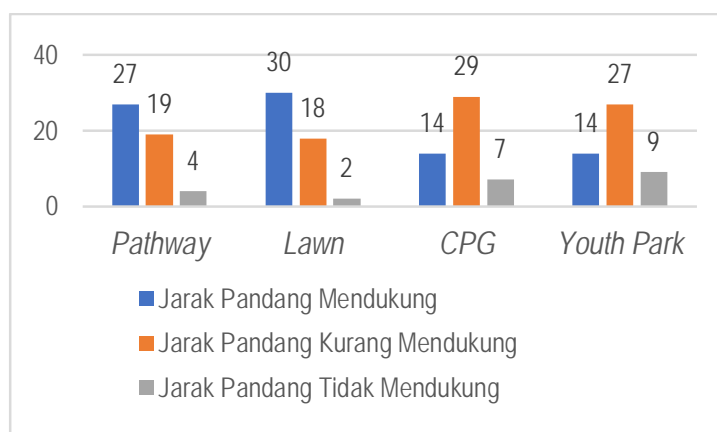

Gambar 4. Diagram Pencahayaan Buatan di Taman Kota Sewaka Dharma berdasarkan Aspek Jarak Pandang

Berdasarkan hasil data kuesioner yang selanjutnya dilakukan uji Chi-Square dapat diketahui bahwa tidak terdapat nilai ekspektasi lebih kecil dari 5 (lima). Nilai ekspektasi terkecil yaitu 5.50 maka syarat uji Chi-Square terpenuhi. Melalui hasil Pearson Chi-Square didapatkan nilai p-value atau Asymp. Sig. sebesar 0.004 dengan a sebesar 0.05 maka nilai $p$-value $<0.05$ atau didapatkan nilai $x^{2}$ hitung sebesar $19.368>x^{2}$ tabel sebesar 12.591, dengan demikian $\mathrm{H} 1$ diterima dan $\mathrm{H} 0$ ditolak, dapat diketahui adanya pengaruh antara pencahayaan buatan di Taman Kota Sewaka Dharma dengan jarak pandang (Rea, 2000). Hal ini berkaitan dengan lampu yang digunakan di area pathway dan lawn sebagian besarnya yaitu lampu dengan tipe pencahayaan umum yang merupakan pencahayaan utama di Taman Kota Sewaka Dharma, sehingga dapat memancar cahaya secara merata dan mampu mendukung aktivitas pengunjung dengan cahaya yang memadai. Pada area CPG, lampu yang digunakan bertipe pencahayaan umum berjumlah 4 (empat) buah, namun cahaya yang dihasilkan di area dengan kegiatan aktif ini kurang maksimal karena terdapat 2 (dua) buah lampu yang tidak menyala dan terdapat vegetasi berstrata pohon yang tumbuh di sisi tengah area sehingga menghalangi arah datangnya cahaya. Oleh karena itu cahaya yang dihasilkan kurang mampu mendukung aktivitas pengunjung dengan cahaya yang kurang memadai. Pada area youth park, lampu yang digunakan sebagian besar bertipe pencahayaan aksen dan pencahayaan efek sehingga cahaya yang dihasilkan juga kurang maksimal. Oleh karena itu cahaya yang dihasilkan kurang mampu mendukung aktivitas pengunjung dengan cahaya yang kurang memadai. Usaha peningkatan kondisi kualitas pencahayaan buatan di Taman Kota Sewaka Dharma khususnya area dengan cahaya kurang memadai, berpotensi meningkatkan jarak pandang pengunjung dalam menikmati fasilitas Taman Kota Sewaka Dharma.

\subsection{Pencahayaan Buatan di Taman Kota Sewaka Dharma berdasarkan Aspek Kenyamanan Visual}

Persepsi pengunjung mengenai pencahayaan buatan di Taman Kota Sewaka Dharma pada malam hari jika ditinjau berdasarkan aspek kenyamanan visual diidentifikasi secara spesifik pada ruang taman kota dengan membagi area Taman Kota Sewaka Dharma menjadi empat bagian, sedangkan aspek kenyamanan visual dibagi menjadi tiga bagian seperti pada Gambar 5.

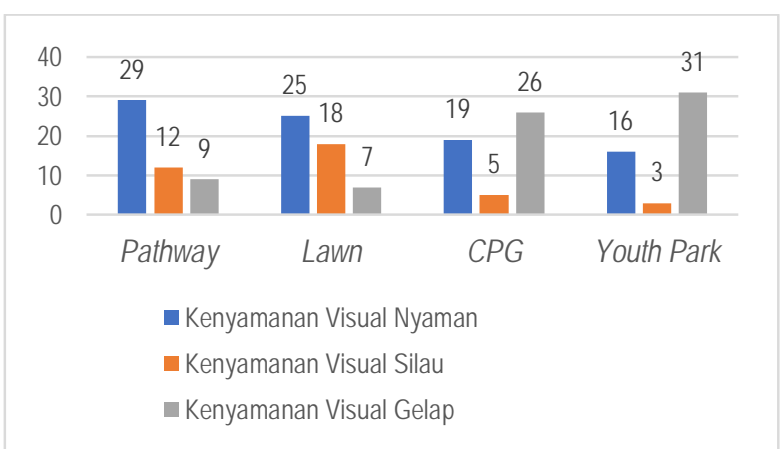

Gambar 5. Diagram Pencahayaan Buatan di Taman Kota Sewaka Dharma berdasarkan Aspek Kenyamanan Visual 
Berdasarkan hasil data kuesioner yang selanjutnya dilakukan uji Chi-Square dapat diketahui bahwa tidak terdapat nilai ekspektasi lebih kecil dari 5 (lima). Nilai ekspektasi terkecil yaitu 9.50 maka syarat uji Chi-Square terpenuhi. Melalui hasil Pearson Chi-Square didapatkan nilai p-value atau Asymp. Sig. sebesar 0.000 dengan a sebesar 0.05 maka nilai $p$-value $<0.05$ atau didapatkan nilai $x^{2}$ hitung sebesar $42.282>x^{2}$ tabel sebesar 12.591, dengan demikian $\mathrm{H} 1$ diterima dan HO ditolak, sehingga dapat diketahui adanya pengaruh antara pencahayaan buatan di Taman Kota Sewaka Dharma dengan aspek kenyamanan visual (Rea, 2000). Usaha peningkatan kondisi kualitas pencahayaan buatan di Taman Kota Sewaka Dharma berpotensi meningkatkan kenyamanan pengunjung dalam menikmati fasilitas Taman Kota Sewaka Dharma. Hal ini berkaitan dengan warna lampu yang digunakan pada area pathway dan lawn sebagian besar yaitu berwarna putih dan kuning sehingga cahaya yang dihasilkan menjadi terang dengan intensitas cahaya yang cukup, menjadikan pengunjung nyaman pada area ini. Pada area CPG, lampu yang digunakan berwarna putih terang, namun cahaya yang dihasilkan di area ini kurang maksimal karena terdapat 2 (dua) buah lampu yang tidak menyala dan terdapat vegetasi berstrata pohon yang tumbuh di sisi tengah area sehingga menghalangi arah datangnya cahaya. Oleh karena itu pengunjung menjadi kurang nyaman dengan kondisi gelap pada area tersebut. Pada beberapa bagian di area youth park lampu yang digunakan menggunakan variasi warna seperti lampu tipe C3 dan C4 sehingga cahaya yang dihasilkan membuat suasana ruang berubah-ubah dengan intensitas cahaya rendah menjadikan area ini terkesan gelap. Lampu di area youth park yang berwarna putih dan kuning sebagian besar memiliki sudut distribusi cahaya sempit seperti lampu tipe A2, C5, C6, dan C7 menjadikan area ini terkesan gelap. Usaha peningkatan kondisi kualitas pencahayaan buatan di Taman Kota Sewaka Dharma khususnya area dengan warna lampu yang gelap, berpotensi meningkatkan kenyamanan pengunjung dalam menikmati fasilitas Taman Kota Sewaka Dharma.

\subsection{Pencahayaan Buatan di Taman Kota Sewaka Dharma berdasarkan Aspek Keamanan}

Pengalaman pengunjung berdasarkan peran pencahayaan buatan di Taman Kota Sewaka Dharma pada malam hari terhadap aspek keamanan ditentukan dengan pembagian area Taman Kota Sewaka Dharma menjadi empat bagian, sedangkan aspek keamanan dibagi menjadi dua bagian seperti pada Gambar 6 .

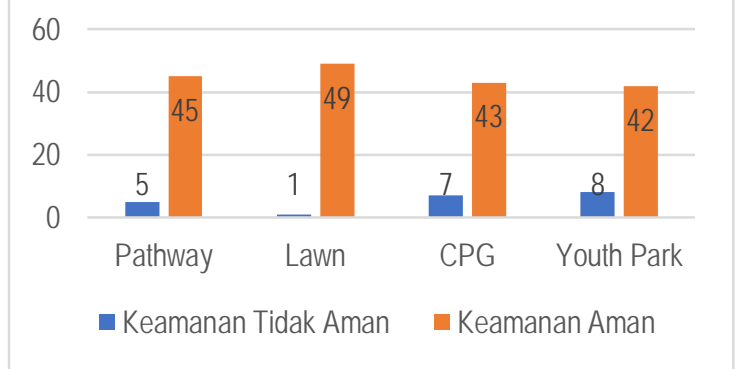

Gambar 6. Diagram Pencahayaan Buatan di Taman Kota Sewaka Dharma berdasarkan Aspek Keamanan

Berdasarkan hasil data kuesioner yang selanjutnya dilakukan uji Chi-Square dapat diketahui bahwa tidak terdapat nilai ekspektasi lebih kecil dari 5 (lima). Nilai ekspektasi terkecil yaitu 5.25 maka syarat uji Chi-Square terpenuhi. Melalui hasil Pearson Chi-Square didapatkan nilai p-value atau Asymp. Sig. sebesar 0.106 dengan a sebesar 0.05 maka nilai $p$-value $>0.05$ atau didapatkan nilai $x^{2}$ hitung sebesar $6.119<x^{2}$ tabel sebesar 7.814 , dengan demikian $\mathrm{H} 1$ ditolak dan $\mathrm{HO}$ diterima, sehingga dapat diketahui dari hasil penilaian oleh pengunjung di Taman Kota Sewaka Dharma tidak terdapat pengaruh antara pencahayaan buatan di Taman Kota Sewaka Dharma dengan aspek keamanan. Hal ini dapat diartikan pula bahwa pencahayaan buatan di Taman Kota Sewaka Dharma sudah memenuhi aspek keamanan sehingga kecil kemungkinan terjadi tindakan yang tidak aman bagi pengunjung (Rea, 2000).

\subsection{Rekomendasi}

Berdasarkan hasil penilaian persepsi dan pengalaman pengunjung terhadap pencahayaan di Taman Kota Sewaka Dharma melalui observasi, uji Chi-Square, analisis deskriptif dan studi pustaka dihasilkan beberapa rekomendasi mengenai pencahayaan di Taman Kota Sewaka Dharma yang dapat meningkatkan rasa nyaman bagi pengunjung dalam melakukan aktivitas, yaitu perlu dilakukan redesain pencahayaan buatan eksisting di area CPG dan youth park seperti pada Gambar 7. 

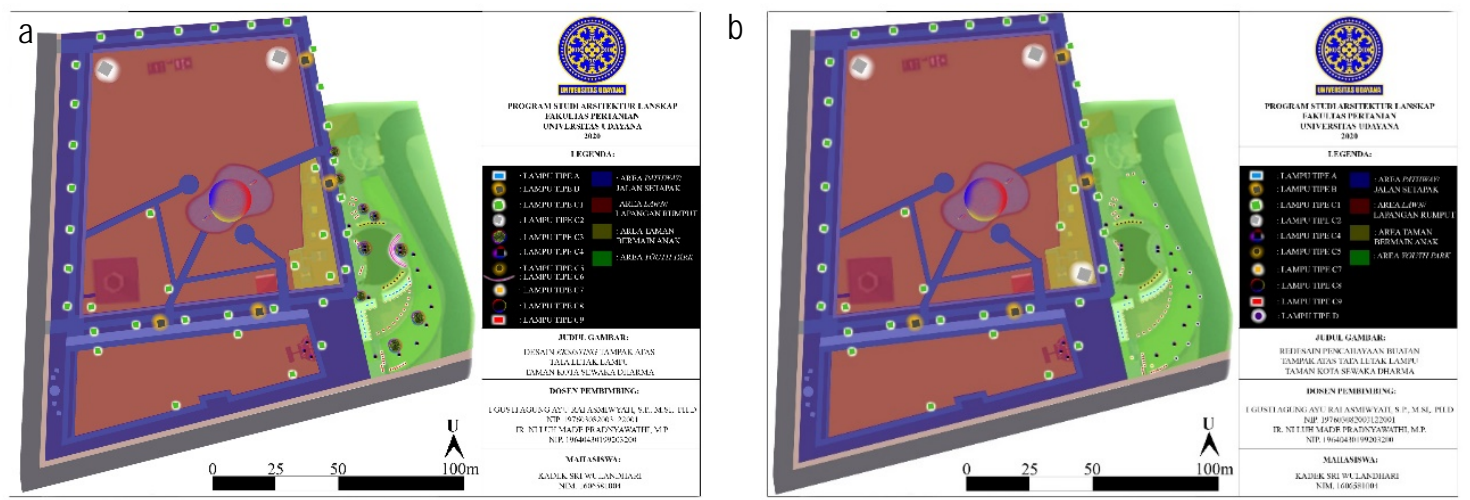

Gambar 7. Tata Letak Lampu Taman Kota Sewaka Dharma (a) Eksisting, (b) Redesain Pencahayaan Buatan

Pada area CPG perlu dilakukan redesain pencahayaan buatan karena lampu yang digunakan adalah lampu tipe $\mathrm{C} 1$ dengan pencahayaan umum berwarna putih yang berjumlah 4 (empat) buah, namun cahaya yang dihasilkan di area ini kurang maksimal karena terdapat 2 (dua) buah lampu yang tidak menyala dan terdapat vegetasi berstrata pohon yang tumbuh di sisi tengah area sehingga menghalangi arah datangnya cahaya. Oleh karena itu cahaya yang dihasilkan kurang mampu mendukung aktivitas pengunjung karena cahaya yang kurang memadai. Untuk mengefisienkan pemasangan lampu direkomendasikan menghilangkan lampu tipe $\mathrm{C} 1$ berjumlah 2 buah pada bagian selatan area CPG dan menambahkan lampu tipe $\mathrm{C} 2$ berwarna putih dengan intensitas cahaya yang tinggi, dan diletakkan di bagian tenggara CPG dengan tiang penyangga yang mengarahkan cahaya ke bawah. Selain itu direkomendasikan vegetasi berstrata pohon di area ini hanya diletakkan di sisi luar area karena dapat mengganggu pencahayaan (Gambar 8).

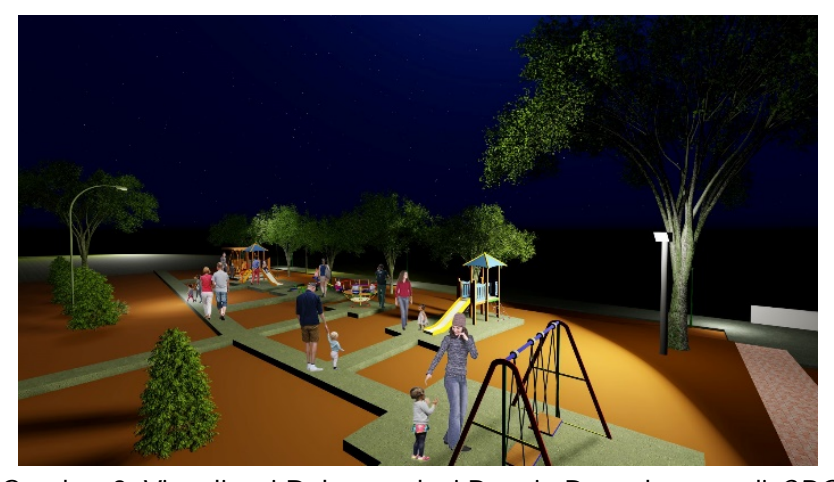

Gambar 8. Visualisasi Rekomendasi Desain Pencahayaan di CPG

Pada area youth park perlu dilakukan rekomendasi karena lampu yang digunakan pada area ini sebagian besar bertipe pencahayaan aksen dan pencahayaan efek. Lampu yang digunakan memiliki variasi warna sehingga cahaya yang dihasilkan membuat suasana ruang berubah-ubah dan terkesan gelap suram. Oleh karena itu dapat direkomendasikan mengganti seluruh lampu tipe C4 dengan variasi warna menjadi kuning cerah untuk menghasilkan kesan ceria, penuh semangat, komunikatif, inspiratif, logis karena youth park merupakan area taman untuk pemuda sehingga dapat membangkitkan kreativitas generasi muda kota Denpasar (Kurniawati, 2008). Selain itu direkomendasikan menghilangkan seluruh lampu tipe C3 yang digantung di vegetasi berstrata pohon pada area ini untuk menghilangkan kesan gelap suram, memasang lampu pada tanaman dapat menyebabkan terjadinya luka pada bagian batang tanaman, hal ini disebabkan oleh gesekan yang terjadi dari pemasangan lampu maupun penggantian lampu. Luka pada tanaman berindikasi dimasuki oleh virus maupun jamur yang dapat menginfeksi tanaman dan tanaman menjadi sakit, hal ini juga berpengaruh terhadap laju pertumbuhan tanaman (Sopialena, 2017).

Redesain pencahayaan buatan pada area youth park dibagi menjadi empat bagian, yaitu:

1 Bagian panggung dilakukan redesain pencahayaan buatan dengan menambahkan lampu tipe $\mathrm{C} 4$ yang diletakkan di belakang plang nama youth park menggunakan tiang yang akan diarahkan ke panggung youth park, dengan cahaya mengarah ke bawah. Hal ini dilakukan agar bagian ini menjadi lebih terang. 
Selain itu untuk mengefisienkan pemasangan lampu direkomendasikan menghilangkan lampu tipe C6 dan lampu tipe C3 yang terletak pada pohon di panggung dan pohon di belakang plang nama youth park. Lampu tipe C4 yang semula menggunakan variasi warna diganti dengan warna kuning cerah (Gambar 9).

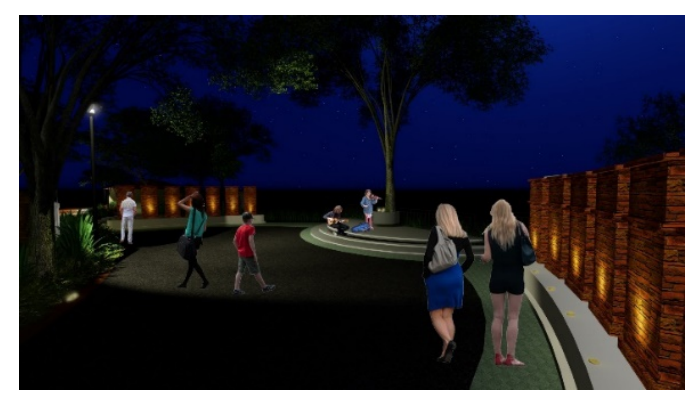

Gambar 9. Visualisasi Rekomendasi Desain Pencahayaan di Bagian Panggung

2 Bagian tangga dekat food center dilakukan redesain pencahayaan buatan dengan mengganti lampu tipe C4 dengan variasi warna menjadi lampu tipe $\mathrm{C} 7$ berwarna puth terang yang diletakkan pada tiang penyangga dengan cahaya mengarah ke bawah. Hal ini dilakukan untuk membuat bagian ini lebih terang (Gambar 10).

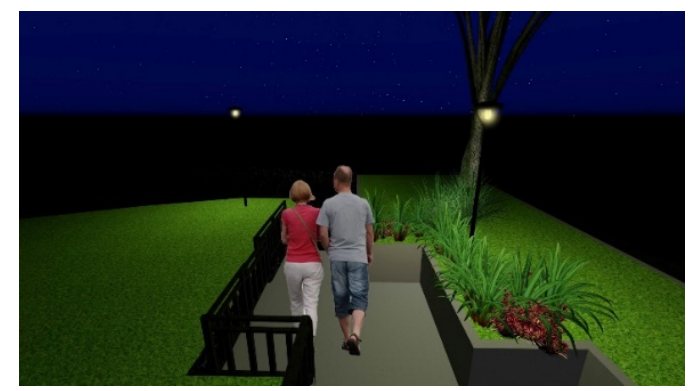

Gambar 10. Visualisasi Rekomendasi Desain Pencahayaan di Bagian Tangga Dekat Food Center

3 Bagian tangga dekat amphitheater dilakukan redesain pencahayaan buatan dengan menambahkan lampu tipe C9 berwarna kuning cerah yang diletakkan pada retaining wall yang bersebelahan dengan tangga dekat amphitheater dan cahaya mengarah ke samping. Hal ini dilakukan karena bagian ini belum terdapat pencahayaan yang mampu menerangi tangga (Gambar 11).

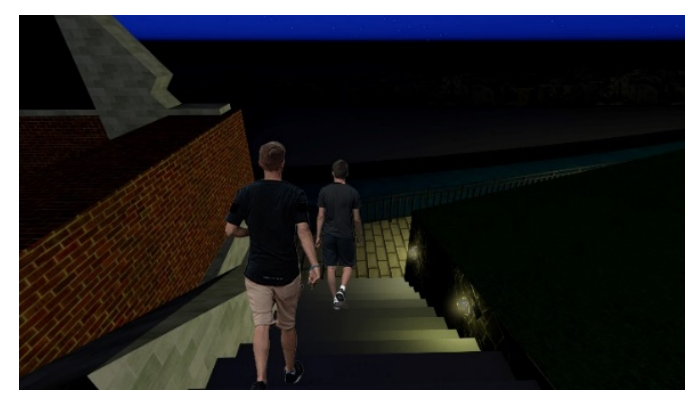

Gambar 11. Visualisasi Rekomendasi Desain Pencahayaan di Bagian Tangga Dekat Amphitheater

4 Bagian jogging track di pinggir Sungai Tagtag dilakukan redesain pencahayaan buatan dengan menambahkan lampu tipe baru, di luar lampu eksisting Taman Kota Sewaka Dharma yaitu lampu pijar berwarna kuning cerah yang diletakkan pada retaining wall dengan cahaya mengarah ke bawah yang disimbolkan dengan lampu tipe D. Penambahan lampu pijar dilakukan karena mampu menciptakan suasana lebih alami. Bagian jogging track di pinggir Sungai Tagtag merupakan bagian yang bersifat alami karena berada di pinggir sungai yang menandakan masih terdapat hewan-hewan nokturnal, karena itu 
perlu memperhatikan intensitas cahaya yang akan dipasang sehingga tidak mengganggu ekosistem yang ada (Sofian, 2020). Penambahan lampu tipe D dilakukan karena bagian ini hanya terdapat lampu dengan sebaran distribusi cahaya sempit sehingga intensitas lampu yang dihasilkan kurang mampu menerangi bagian ini (Gambar 12).

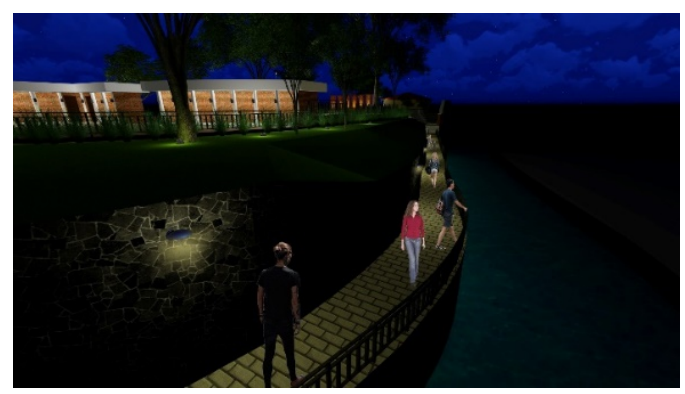

Gambar 12. Visualisasi Rekomendasi Desain Pencahayaan di Bagian Jogging Track di Pinggir Sungai Tagtag

\section{Simpulan dan Saran}

\subsection{Simpulan}

Lampu-lampu yang ada di Taman Kota Sewaka Dharma jika ditinjau berdasarkan sumber material terbagi menjadi tiga jenis yaitu fluoresens, HID, dan LED. Lampu fluoresens di Taman Kota Sewaka Dharma jika ditinjau berdasarkan arah pencahayaan, kebutuhan dan fungsinya terbagi atas satu tipe, lampu HID menjadi satu tipe dan lampu LED terbagi atas sembilan tipe.

Persepsi dan pengalaman pengunjung terhadap pencahayaan di Taman Kota Sewaka Dharma yang diuji lebih lanjut melalui uji Chi-Square menunjukkan pencahayaan buatan memberikan pengaruh pada aspek jarak pandang dan aspek kenyamanan visual pengunjung, namun tidak memiliki pengaruhnya dengan pengalaman keamanan pengunjung di Taman Kota Sewaka Dharma. Hal ini berimplikasi pada tindakan redesain seperti aspek jarak pandang berpengaruh pada pemilihan tipe lampu, serta aspek kenyamanan visual berpengaruh pada pemilihan warna dan distribusi cahaya.

Rekomendasi yang dapat diberikan yaitu dengan melakukan redesain pencahayaan buatan pada area yang memiliki pengaruh tinggi dalam menunjang kebutuhan manusia dari aspek jarak pandang dan kenyamanan visual yaitu pada area CPG dan youth park.

\subsection{Saran}

Pencahayaan buatan di Taman Kota Sewaka Dharma perlu ditunjang dengan peningkatan pemeliharaan agar fungsi pencahayaan tetap terjaga dan dapat meningkatkan rasa nyaman bagi pengunjung. Penelitian ini hanya memberikan rekomendasi pencahayaan berdasarkan persepsi dan pengalaman pengunjung yang ditinjau melalui indikator jarak pandang, kenyamanan visual, dan keamanan. Penelitian ini dapat dilanjutkan dengan membuat rekomendasi berdasarkan illuminasi pencahayaan.

\section{Daftar Pustaka}

Hadi, S. (2000). Statistik Jilid 2. Yogyakarta Andi. Yogyakarta.

Handayani, S. (2009). Arsitektur Lansekap. Modul Kuliah Arsitektur (published) Universitas Pendidikan Indonesia.

Istijanto. (2005). Aplikasi Praktis Riset Pemasaran. PT. Gramedia Pustaka Utama. Jakarta.

Kurniawati, L. 2008. Pengaruh Pencahayaan L.E.D terhadap Suasana Ruang Cafe dan Restoran. Skripsi (published) Universitas Indonesia.

Rea, M. (2000). The IESNA Lighting Handbook : Reference \& Application (9th ed.). Illuminating Engineering Society of North America. New York.

Soegoto, E. S. (2013). Marketing Research The Smart Way to Solve a Problem. Elex Media Komputindo. Jakarta.

Sofian, D. H. (2020). Landscape and Lighting Entertaiment in Waterscape and Lightscape. Himpunan Teknik Iluminasi Indonesia. Available online at: https://www.youtube.com/watch?v=TvYDfcE9IQE\&t=8454s (diakses pada 8 October 2020).

Sopialena. (2017). Segitiga Penyakit Tanaman. Mulawarman University Press. Samarinda. 